\title{
, \\ Molecular Genetic Investigation of Digital Melanoma in Dogs
}

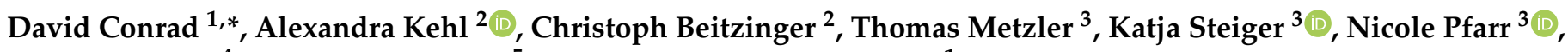 \\ Konrad Fischer ${ }^{4}$, Robert Klopfleisch ${ }^{5}$ and Heike Aupperle-Lellbach ${ }^{1}$
}

1 Department of Pathology, LABOKLIN GmbH \& Co. KG, 97688 Bad Kissingen, Germany; aupperle@laboklin.com

2 Department of Molecular Biology, LABOKLIN GmbH \& Co. KG, 97688 Bad Kissingen, Germany; kehl@laboklin.com (A.K.); beitzinger@laboklin.com (C.B.)

3 Institute of Pathology, School of Medicine, Technische Universität München, 81675 München, Germany; thomas.metzler@tum.de (T.M.); katja.steiger@tum.de (K.S.); nicole.pfarr@tum.de (N.P.)

4 School of Life Sciences Weihenstephan, Technische Universität München, 85354 Freising, Germany; konrad.fischer@tum.de

5 Department of Pathology, Freie Universität Berlin, 14163 Berlin, Germany; Robert.Klopfleisch@fu-berlin.de

* Correspondence: conrad@laboklin.com

Citation: Conrad, D.; Kehl, A.; Beitzinger, C.; Metzler, T.; Steiger, K.; Pfarr, N.; Fischer, K.; Klopfleisch, R.; Aupperle-Lellbach, H. Molecular Genetic Investigation of Digital Melanoma in Dogs. Vet. Sci. 2022, 9, 56. https://doi.org/10.3390/ vetsci9020056

Academic Editor: David J. Argyle

Received: 6 December 2021

Accepted: 26 January 2022

Published: 30 January 2022

Publisher's Note: MDPI stays neutral with regard to jurisdictional claims in published maps and institutional affiliations.

Copyright: (C) 2022 by the authors. Licensee MDPI, Basel, Switzerland. This article is an open access article distributed under the terms and conditions of the Creative Commons Attribution (CC BY) license (https:// creativecommons.org/licenses/by/ $4.0 /)$.

\begin{abstract}
Canine digital melanoma, in contrast to canine oral melanoma, is still largely unexplored at the molecular genetic level. The aim of this study was to detect mutant genes in digital melanoma. Paraffin-embedded samples from 86 canine digital melanomas were examined for the BRAF V595E variant by digital droplet PCR (ddPCR), and for exon 11 mutations in $c$-kit. Furthermore, exons 2 and 3 of KRAS and NRAS were analysed by Sanger sequencing. Copy number variations (CNV) of KITLG in genomic DNA were analysed from nine dogs. The BRAF V595E variant was absent and in $c$-kit, a single nucleotide polymorphism was found in 16/70 tumours (23\%). The number of copies of KITLG varied between 4 and 6. KRAS exon 2 codons 12 and 13 were mutated in 22/86 $(25.6 \%)$ of the melanomas examined. Other mutually exclusive $R A S$ mutations were found within the hotspot loci, i.e., KRAS exon 3 codon 61: 2/55 (3.6\%); NRAS exon 2 codons 12 and 13: 2/83 (2.4\%); and NRAS exon 3 codon 61: 9/86 (10.5\%). However, no correlation could be established between histological malignancy criteria, survival times and the presence of $R A S$ mutations. In summary, canine digital melanoma differs from molecular genetic data of canine oral melanoma and human melanoma, especially regarding the proportion of $R A S$ mutations.
\end{abstract}

Keywords: canine; acral; mutation; tumour; BRAF; KRAS; NRAS; c-kit; CNV; KITLG

\section{Introduction}

Melanomas are malignant neoplasms originating from melanocytes and are often found in the oral cavity, on the skin, at the eyes or the digits [1]. Pathogenesis of canine melanocytic neoplasms depends on the site [1] and the coat colour [2]. Furthermore, occurrence, breed predisposition and prognosis vary depending on the site of melanocytic neoplasms [1]. Cutaneous and ocular melanocytic neoplasms are mainly benign [1,3] and are commonly located at the head, ventral abdomen, scrotum or the eye [1]. In contrast, oral melanomas are highly aggressive, and benign variants are rare [1,4]. Melanocytic neoplasms of the toe have an intermediate aggressiveness: Nishiya et al. [1] stated that they appear to be malignant in $5-58 \%$ of cases. Breed predispositions have been described in Schnauzers [5], Irish Setters [5,6], Golden Retrievers [6], Rottweilers and Labrador Retrievers [7].

Various mutations have already been identified in human melanoma and to some extent also in canine melanoma, as explained below. In humans, the BRAF V600E variant is well known as a common cause of tumour formation, as it is a $\mathrm{T}$ to $\mathrm{A}$ transversion in exon 15 , resulting in the amino acid substitution of valine by glutamic acid at codon 600 [8,9]. This BRAF variant, in the past also referred to as V599E, is detectable in about $60 \%$ of human 
melanomas [10-13] and activates MEK as a part of the mitogen-activated protein kinase (MAPK) pathway [8]. This variant is of special therapeutic interest, because vemurafenib, an inhibitor specifically targeting the activated step of the MAPK pathway induced by the mutated BRAF protein, is available, and treating human melanoma patients with this drug results in a transient remission of the disease [14,15]. The canine BRAF V595E mutation is orthologous to human $B R A F \mathrm{~V} 600 \mathrm{E}$ with a transversion from $\mathrm{T}$ to $\mathrm{A}$ in exon 15 [9]. This somatic mutation was specifically found in canine urothelial and prostatic carcinoma, but only rarely in other canine tumours [9].

The MAPK pathway is activated by RAS genes and RAS proteins (especially KRAS/ NRAS/HRAS) are upstream of the RAF proteins within the signal transduction [8]. According to a review by Downward [16], RAS proteins show somatic mutations in human cancer in up to $20 \%$ of cases. Point mutations in codons 12,13 and 61 within the RAS genes have already been identified as oncogenes in human cancers [17]. In human melanomas, mutations of NRAS (10-15\%) and KRAS (2\%) are detectable, with NRAS having the substitution $\mathrm{L} 61 \mathrm{Q}$ in about $80 \%$ of cases while G12V accounts for about $77 \%$ of the KRAS mutations according to a review by Cicenas et al. [18]. Molecular genetic studies are also available for human acral melanoma. NRAS mutations are frequently found (27.9\%), while HRAS or KRAS mutations are only present in less than 5\% of cases [19]. Mayr et al. [20] identified NRAS exon 2 codon 61 mutations in 2 of 16 dogs with cutaneous malignant melanoma, located in lumbar and scrotal regions. In contrast to this, Escobar et al. [21] did not find any KRAS or NRAS mutations in 11 canine malignant melanomas (site not reported). Additionally, $R A S$ mutations have been described in two canine cutaneous melanomas (one KRAS and one NRAS) and in three melanomas of the digits (two KRAS and one NRAS) [22].

The proto-oncogene $c$-kit encodes the transmembrane receptor tyrosine kinase c-Kit (CD117) [23], while KITLG encodes stem cell factor (SCF) as a ligand of the tyrosinekinase receptor c-Kit [24]. c-Kit is expressed in numerous cell types such as mast cells, melanocytes, and interstitial cells of Cajal [25]. In melanocytes, the proto-oncogene $c$-kit is thought to be involved in the regulation of pigmentation, migration, differentiation, survival, and proliferation [25]. Mutations of this gene have been identified in human mucosal melanoma [26-28] and also in human acral melanoma [26,28]. In canine melanoma, gain-of-function $c$-kit mutations have been found in a limited number of cases [29-31]. Smedley et al. [30] identified 85 variants in $c$-kit in canine oral melanomas, including 9 non-synonymous mutations.

KITLG is physiologically involved in postnatal cutaneous melanogenesis and in the terminal differentiation of follicular epithelial melanocytes, making it significant for the determination of canine coat colour [32]. Karyadi et al. [33] identified a copy number variation (CNV) at the KITLG locus, which is likely to be responsible for the high risk of black Poodles to develop digital squamous cell carcinoma (DSCC). They found an increased risk for DSCC in dogs with more than four copies of the KITLG gene. Dark-coloured dogs have a well-known predisposition for DSCC, which also shows a more aggressive histological picture in such breeds [34]. KITLG mutations have not been investigated in canine melanoma so far.

As it is generally known that there are differences between melanocytic neoplasms of different sites [1], the first oncogenetic studies of canine oral melanoma may not be representative for digital melanoma in dogs. In addition, the number of canine digital melanomas that have been addressed in the available literature is small [5,35-37]. Thus, the aim of our retrospective study was to investigate the occurrence of genetic aberrations of BRAF, c-kit, KITLG, NRAS and KRAS in canine digital melanoma. The hypothesis was that their oncogenic mechanisms may differ from melanomas of other sites, particularly oral ones. Furthermore, the molecular genetic results should be compared to their human counterparts. For this we used formalin-fixed toes with melanomas, which were submitted for routine diagnostics during the years 2014-2021 to Laboklin GmbH \& Co. KG, Bad Kissingen, Germany and corresponding blood samples as far as available. 


\section{Materials and Methods}

Malignant melanomas of the toe/nailbed from 86 dogs were included in this retrospective study. Inclusion criteria were a clear histopathological diagnosis and the availability of a paraffin-embedded tumour block before decalcification. Melanomas of the skin of the limb which did not affect the nailbed, or the bone were excluded. Age, sex, breed and further information, if available, were collected. For additional information, the veterinarians were contacted by telephone. Coat colour, exact site of the digital mass and a short report of the clinical course were documented whenever possible.

Blood samples of nine dogs with digital melanoma were available from routine diagnostics (presurgical or geriatric screening). As all samples (toes and blood) were submitted for routine diagnostic purposes, ethics committee approval was not required. All the material used was no longer needed for diagnostics.

\subsection{Histopathology}

Claws were trimmed according to Kamstock et al. [38] and decalcified using Osteomoll ${ }^{\circledR}$ rapid decalcifier solution for histology (Merck, Darmstadt, Germany) over a period of $24-72 \mathrm{~h}$. Representative sample sites were embedded in paraffin wax and processed for routine histopathological examination according to standard procedures. From each toe, one non-decalcified tumour site was used for further molecular genetic investigations. Sections were stained with haematoxylin and eosin (HE) and histologically evaluated by trained veterinary pathologists during routine diagnostics and reevaluated by H.A.-L. Bleaching with $30 \% \mathrm{H}_{2} \mathrm{O}_{2}$ was performed for $24-72 \mathrm{~h}$, if necessary, to detect nuclear atypia or mitoses if pigmentation was too intensive. Representative sites were characterised according to morphological criteria (pigmentation, mitotic count, nuclear atypia, and histomorphological type) as described by Spangler and Kass [3].

\subsection{Molecular Genetic Methods}

\subsubsection{BRAF Mutation, c-kit Gene Mutation}

Paraffin-embedded samples were prepared for DNA extraction using the QIAamp ${ }^{\circledR}$ DNA FFPE Tissue Kit (Qiagen, Hilden, Germany) according to the manufacturer's instructions. Isolated DNA was examined for the presence of the BRAF mutation c. $1784 \mathrm{~T}>\mathrm{A}$ by digital droplet polymerase chain reaction (ddPCR) using a mutation-specific TaqMan ${ }^{\circledR}$ assay as described by Mochizuki et al. [39]. Analysis was performed using DropletReader (Bio-Rad, Feldkirchen, Germany) and QuantaSoft ${ }^{\mathrm{TM}}$ Software (Bio-Rad, Feldkirchen, Germany). The sequence of exon 11 of c-kit (ENSCAFT00030034940.1) was analysed by PCR amplification and subsequently by Sanger sequencing. Primers are listed in Table 1. Bidirectional Sanger sequencing of all PCR products was performed on an ABI 3130 Genetic Analyzer (Life Technologies, Carlsbad, CA, USA) using the BigDye Terminator v1.1 Cycle Sequencing Kit (Life Technologies, Carlsbad, CA, USA) according to standard protocols. Mutational screening for BRAF and c-kit was done at the Department of Molecular Biology, Laboklin GmbH \& Co. KG, Bad Kissingen, Germany.

\subsubsection{NRAS/KRAS Mutation Analysis}

Referring to the genome CanFam3.1, melanoma samples were analysed for mutations in exons 2 and 3 of NRAS (ENSCAFT00000015144.4) and KRAS (ENSCAFT00000010525.4), respectively, by Sanger sequencing at the Institute of Pathology, Technische Universität München, Germany. DNA was isolated from a microdissected section of a tumour tissue block from areas in which a high tumour cell concentration (at least $60 \%$ tumour cell content, median: $80 \%$, range: $60-95 \%$ ) had been microscopically identified. DNA isolation was performed using the Maxwell 16 RSC extraction system (Promega, Madison, WI, USA). DNA quantity was measured by a QuBit 4.0 system and the QuBit high sensitivity assay (both: Thermo Fisher Scientific, Waltham, MA, USA). All exons were amplified with the primers listed in Table 1 and with 10-20 ng of DNA as input and an annealing temperature of $60^{\circ} \mathrm{C}$. Bidirectional Sanger sequencing of all PCR products was subsequently conducted 
on an ABI 3100 Genetic Analyzer (Life Technologies, Carlsbad, CA, USA) using the BigDye Terminator v1.1 Cycle Sequencing Kit (Life Technologies, Carlsbad, CA, USA) according to standard protocols.

Table 1. Primer/Probe sequences used for the analysis of NRAS, KRAS, c-kit and KITLG genes.

\begin{tabular}{|c|c|c|}
\hline Gene & Primer/Probe & Sequence \\
\hline \multirow{2}{*}{ NRAS exon 2} & Forward & 5'-CGCCCATTAAACCTAATTGC-3' \\
\hline & Reverse & 5'-ACCAAAAGCCAGAGGTAGGG-3' \\
\hline \multirow{2}{*}{ NRAS exon 3} & Forward & 5'-АТСТССТАСССТССАСАССС-3' \\
\hline & Reverse & 5'-GGCAAATACACAGAGGAAGCC-3' \\
\hline \multirow{2}{*}{ KRAS exon 2} & Forward & 5'-AAAAGGTGTTGATAGAGTGGGTTATAC-3' \\
\hline & Reverse & 5'-AAATGGGCCTGCACAAATC-3’ \\
\hline \multirow{2}{*}{ KRAS exon 3} & Forward & 5'-ACTGTGTTTCTCCCTTCTCAGG-3' \\
\hline & Reverse & 5'-GCCCTCGATGTCATTTTATTATATTC-3' \\
\hline \multirow{2}{*}{ c-kit exon 11} & Forward & 5'-CCCATGTATGAAGTACAGTGGAAG-3' \\
\hline & Reverse & 5'-GTTCCCTAAAGTCATTGTTACACG-3' \\
\hline \multirow{3}{*}{ CNV KITLG } & Forward & 5'-TGCACAAGGGAGAAGGGTTG-3' \\
\hline & Reverse & 5'-AGATGGTCCTGGGGAAACCA-3' \\
\hline & Probe & 5'-FAM-TGGCTGGGGACAGAAGCAATG-BBQ650-3' \\
\hline
\end{tabular}

\subsubsection{Copy Number Variation Analysis of KITLG}

Genomic DNA was isolated from ethylenediaminetetraacetic acid (EDTA) blood with the MagNA Pure 96 system using a DNA Tissue Lysis Buffer and viral NA Small kit (Roche, Basel, Switzerland) according to the manufacturer's instructions. Copy number quantification of the KITLG-CNV was performed by ddPCR using TaqMan ${ }^{\circledR}$ assays specific for the KITLG-CNV sequence and proto-oncogene 1 (ETS1) as reference gene as described by Bannasch et al. [32]. An additional assay was designed for KITLG-CNV using the CanFam3.1 reference genome. Primers and the probe are listed in Table 1. The copy number was determined using DropletReader (Bio-Rad, Feldkirchen, Germany) and QuantaSoft ${ }^{\mathrm{TM}}$ Software (Bio-Rad, Feldkirchen, Germany). Analysis of the samples was performed at the Department of Molecular Biology, Laboklin GmbH \& Co. KG, Bad Kissingen, Germany; with both assays and ETS1 as reference, each in duplicate. Two independent in-house studies consistently demonstrated that both the inter- and intra-assay spearman correlation between the two methods (Bannasch et al. [32] and Karyadi et al. [33]) was highly significant $(p<0.001)$. Therefore, we calculated the median from all four measurements (two per method) to obtain robust CNV estimates.

\subsection{Statistical Analysis}

Statistical significance analyses were evaluated using IBM SPSS Statistics (version 26). Comparisons between RAS mutations (KRAS and NRAS combined) and KRAS and the characteristics of degree of pigmentation, mitotic count and degree of nuclear atypia were performed with the Mann-Whitney $\mathrm{U}$ test. The association of RAS / KRAS mutations and histomorphological type was investigated by Fisher's exact test. The value $p<0.05$ was considered statistically significant. Survival times were determined using the Kaplan-Meier plot and matched by the logrank test. The significance level was $p<0.05$, the number of degrees of freedom was 1.

\section{Results}

\subsection{Case Description, Clinical Data, and Survival Time}

Toes from 86 dogs were collected for the study. Clinical data were often incomplete because the animals were only presented to the clinics for toe amputation. As far as available, details are listed in the suppl. Table. The age ranged from five to 15 years, with a 
median of 11 years. In three cases, the age was unknown. The cohort included 36 intact and 15 castrated male dogs as well as 18 intact and 16 spayed female dogs. Sex was unknown in one case. The following breeds were represented: 23 mongrels, 15 Labrador Retrievers, 10 Giant Schnauzers, seven Rottweilers, four Golden Retrievers, three Irish Terriers, three Sheepdogs (not specified), two Bernese Mountain Dogs, two Cocker Spaniels and two Poodles. There was one animal of each of the following breeds: Airedale Terrier, Belgian Shepherd, Bullmastiff, Cairn Terrier, Cane Corso, Doberman, French Bulldog, German Hunting Terrier, German Shepherd, Gordon Setter, Havanese, Miniature Schnauzer, Pinscher, Scottish Terrier, and a Tibetan Terrier. A large proportion of the animals had a black coat colour $(n=31)$. The others were black \& $\tan (n=15)$, yellow $(n=8)$, fawn $(n=6)$, brown $(n=5)$, tricolour $(n=2)$ and white $(n=2)$. In 17 cases, the coat colour could not be verified anymore.

Melanomas affected the forelimb $(n=54)$ more often than the hindlimb $(n=23)$. In nine cases, the relevant information could not be retrieved. The further clinical course as well as the current health status could be determined in 66 cases and were unknown in the remaining 20 cases. At the time of data collection, 15 dogs were still alive with a median follow-up time of 137 days (range: 19-639 days). 22 animals died because of progressive tumour disease with associated metastasis. Metastases were not clearly localised $(n=11)$, affected the lungs $(n=9)$, spinal cord $(n=1)$, or the tail $(n=1)$. Another 29 dogs died for other reasons (e.g., cardiac or renal insufficiency). Of all dogs that died, the one-year survival rate was $24 \%$ (12 dogs) and the two-year survival rate was $12 \%$ (6 dogs). Within the group of animals that died with reported metastasis, three (14\%) survived one year and one $(5 \%)$ survived two years.

\subsection{Pathological Findings}

The melanomas of the toes were mostly $0.5-2.0 \mathrm{~cm}$ in diameter, but some neoplasms reached a size of up to $5.5 \times 5.5 \times 5.5 \mathrm{~cm}$. The claw was detached in $40 \%$ of cases. Neoplasms affected the nailbed or the paw, and distal phalanges were mostly destructed (Figure 1). The degree of pigmentation was low $(n=48)$, moderate $(n=17)$, intense $(n=6)$ or varied greatly within the neoplasm $(n=15)$ (Figure $1 d)$. In 60 tumours, $2-15$ mitotic figures/10 high-power field (HPF) were counted. In 20 tumours, the mitotic count was 21-39/10 HPF and in six cases, the mitotic count was 44-65/10 HPF (Table S1). Nuclear atypia was mild $(n=14)$, moderate $(n=48)$ or severe $(n=24)$. Most melanomas had a dominant epithelioid morphology $(n=44)$. In 14 cases, the tumour cells were mostly spindle-shaped. Round cell morphology $(n=9)$ or balloon cell type $(n=1)$ were rare. In the remaining 18 cases, morphology was a mixture of these types. Margins were clean in 69 dogs, narrow ( $<3 \mathrm{~mm}$ ) in seven tumours and infiltrated by tumour cells in 10 cases.

The different histological criteria were statistically analysed with regard to their influence on the median survival time. Dogs with melanomas larger than $1 \mathrm{~cm}$ in diameter (median: 151 days; $n=11$ ) and those with tumour cells detectable at the surgical margins (median: 72 days; $n=4$ ) had lower survival times than animals with smaller melanomas (median: 274 days; $n=5$ ) and clean margins (median: 183 days; $n=15$ ). However, due to the low number of cases, statistical significance was not reached.

\subsection{Genetic Analysis}

Wild type BRAF V595E was detected in 81 samples. In five cases, PCR failed, as not enough DNA could be extracted for amplification.

In 16 of 70 melanomas, we identified a silent $c$-kit gene alteration in exon 11 . In 16 other samples, no PCR product could be amplified. The $c-k i t$ variant in exon 11 was c.1731C > T (counterpart in human molecular pathology: p.Y577Y) and either heterozygous $(n=10)$ or homozygous $(n=6)$. This variant corresponds to a putative germline variant listed in ENSEMBL (SNP-No.: rs853024368; https: / / www.ensembl.org/index.html, accessed on 22 November 2021). 


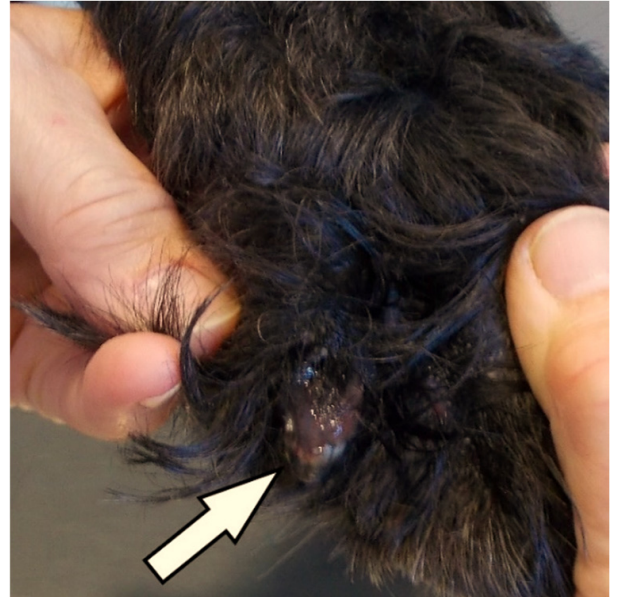

(a)

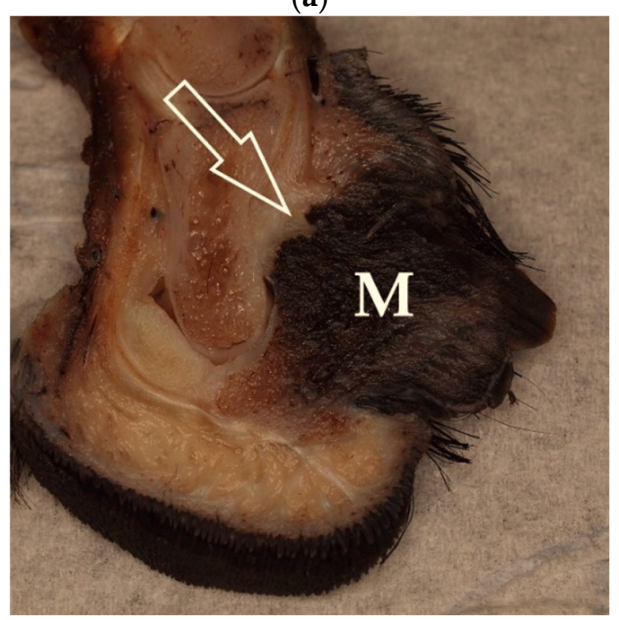

(c)

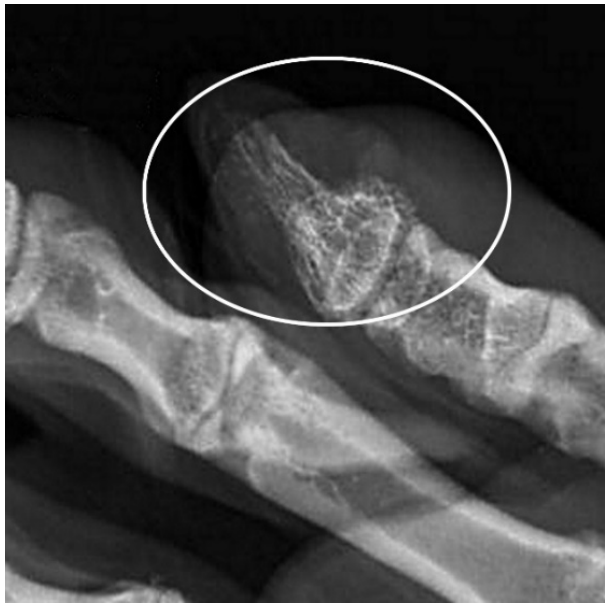

(b)

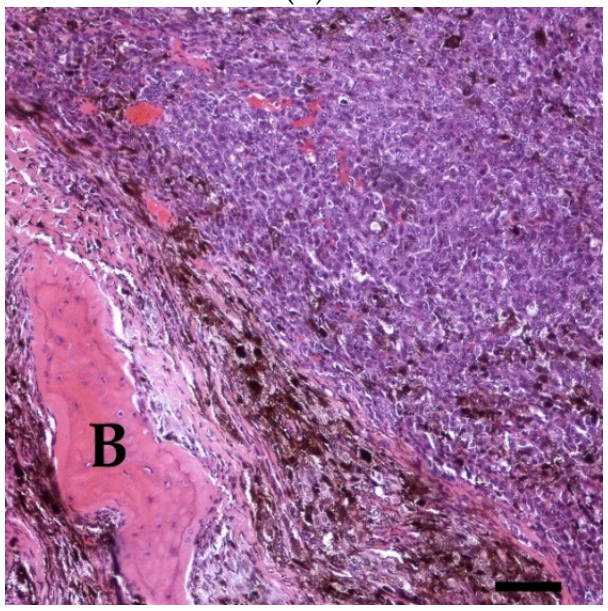

(d)

Figure 1. Malignant melanoma of the fifth toe of the hindlimb of a 10-year-old Giant Schnauzer (Dog No. 48): (a) The claw horn has detached and the neoplastic tissue is exposed (arrow; (c) Dr. Blasberg, Kleintierpraxis Bad Honnef); (b) The claw bone shows significant osteolysis in the X-ray (circle; (c) Dr. Blasberg, Kleintierpraxis Bad Honnef); (c) Longitudinal cut of the formalin-fixed amputated digit with a $1.4 \times 1.0 \times 1.4 \mathrm{~cm}$ black mass $(\mathrm{M})$ originating from the nailbed and infiltrating the bone (arrow); (d) Histologically, the neoplastic cells show varying degrees of pigmentation and infiltration of the bone $(\mathrm{B})(\mathrm{HE}, \mathrm{bar}=200 \mu \mathrm{m})$.

In $K R A S$ and NRAS genes, exons 2 and 3 were amplified and sequenced. Most mutations were detected in the KRAS gene (Table 2). All identified RAS mutations were mutually exclusive-combinations did not occur.

KRAS mutations in exon 2 (codons 12 and 13) were found in 22 cases which are listed in Table 3. KRAS mutations in exon 3 (codon 61) were found in the mixed cell type melanoma of the third toe of the right forelimb of an eight-year-old male German Shepherd (No. 80; survival time: 55 days) and in one round cell type melanoma of the fifth toe of the right forelimb of an eight-year-old female mongrel (No. 9; survival time: 110 days). The amount of pigments was moderate in the first case and low in the second. The mitotic count was 31/10 HPF in the German Shepherd and 5/10 HPF in the mongrel. 
Table 2. Overview of all cases with detected RAS mutation $(n=35)$.

\begin{tabular}{cccc}
\hline Gene & Mutation & Wild Type & Not Done \\
\cline { 1 - 1 } KRAS exon 2 codon 12 & 17 & 64 & 0 \\
\hline KRAS exon 2 codon 13 & 5 & 53 & 31 \\
\hline KRAS exon 3 codon 61 & 2 & 81 & 3 \\
\hline NRAS exon 2 codon 12 & 1 & 77 & 0 \\
\hline NRAS exon 2 codon 13 & 1 & 9 & \\
\hline
\end{tabular}

Table 3. Characteristics of dogs with KRAS exon 2 mutation (codons 12 and 13) in digital melanoma $(n=22)$.

\begin{tabular}{|c|c|c|c|c|c|c|c|c|c|}
\hline Dog No. & Codon & Breed (Coat Colour) & Age (y) & Sex & Toe & Morphology & $\begin{array}{l}\text { Pigment } \\
\text { (Degree) }\end{array}$ & $\begin{array}{c}\text { Mitoses/ } \\
10 \mathrm{HPF}\end{array}$ & $\begin{array}{l}\text { Survival } \\
\text { Time (d) }\end{array}$ \\
\hline 40 & 12 & GS & 11 & $\mathrm{MC}$ & $\mathrm{RF}$ & mixed & 2 & 7 & 157 \\
\hline 39 & 12 & GS & 8 & $\mathrm{M}$ & LF & epithelioid & 2 & 3 & 72 \\
\hline 25 & 12 & LR & 12 & M & $\mathrm{RH}$ & epithelioid & 1 & 13 & 338 \\
\hline 26 & 12 & LR (U) & 12 & $\mathrm{~F}$ & LF & spindle cell & 1 & 4 & 274 \\
\hline 27 & 12 & LR (black) & 14 & M & RF & epithelioid & 1 & 5 & $\mathrm{~A}$ \\
\hline 24 & 12 & LR (yellow) & 10 & FS & RF & epithelioid & 1 & 5 & 1304 \\
\hline 49 & 12 & RW & 8 & $\mathrm{~F}$ & RF & epithelioid & 1 & 24 & $\mathrm{U}$ \\
\hline 77 & 12 & $\mathrm{DM}$ & $\mathrm{U}$ & $\mathrm{F}$ & $\mathrm{LF}$ & mixed & 2 & 5 & $\mathrm{U}$ \\
\hline 75 & 12 & $\mathrm{CT}$ & 11 & $\mathrm{MC}$ & LF & epithelioid & $\mathrm{V}$ & 7 & 1016 \\
\hline 73 & 12 & BS & 9 & M & LH & epithelioid & 1 & 13 & A \\
\hline 1 & 12 & MG (black) & 13 & M & $\mathrm{LF}$ & mixed & 1 & 58 & $\mathrm{U}$ \\
\hline 2 & 12 & MG (U) & 8 & $\mathrm{MC}$ & RF & epithelioid & 1 & 25 & 40 \\
\hline 3 & 12 & $\mathrm{MG}(\mathrm{U})$ & 10 & $\mathrm{~F}$ & $\mathrm{LF}$ & round & 1 & 15 & 142 \\
\hline 4 & 12 & MG (U) & 9 & FS & RF & mixed & 2 & 22 & $\mathrm{U}$ \\
\hline 5 & 12 & MG (U) & 9 & M & $\mathrm{RH}$ & epithelioid & 3 & 3 & 1079 \\
\hline 6 & 12 & MG (U) & 13 & $\mathrm{M}$ & $\mathrm{U}$ & round & 1 & 22 & $\mathrm{~A}$ \\
\hline 7 & 12 & MG (b\&t) & 9 & $\mathrm{~F}$ & $\mathrm{LF}$ & epithelioid & 3 & 4 & 189 \\
\hline 8 & 13 & MG (U) & 10 & $\mathrm{MC}$ & $\mathrm{RH}$ & epithelioid & $\mathrm{V}$ & 9 & A \\
\hline 50 & 13 & RW & 5 & $\mathrm{~F}$ & $\mathrm{U}$ & epithelioid & 1 & 65 & 194 \\
\hline 51 & 13 & RW & 11 & $\mathrm{M}$ & $\mathrm{LH}$ & epithelioid & 1 & 15 & 18 \\
\hline 28 & 13 & LR (black) & 12 & $\mathrm{M}$ & LH & epithelioid & 1 & 9 & 504 \\
\hline 82 & 13 & Havanese & 15 & $\mathrm{M}$ & LH & round & 1 & 23 & $\mathrm{U}$ \\
\hline
\end{tabular}

Abbreviations: y: years; d: days; M: male; MC: male castrated; F: female; FS: female spayed; RF: right forelimb RH: right hindlimb; LF: left forelimb; LH: left hindlimb; U: unknown; A: alive; V: varying; b\&t: black and tan; BS Belgian Shepherd; CT: Cairn Terrier; DM: Doberman; GS: Giant Schnauzer; LR: Labrador Retriever; MG: mongrel; RW: Rottweiler.

NRAS mutations in exon 2 (codons 12 and 13) were detected in digital melanomas of the right forelimbs of two Golden Retrievers. Codon 12 mutation was found in a low pigmented, epithelioid melanoma with 8 mitoses /10 HPF of an eight-year-old male Golden Retriever (No. 56; unknown survival time). Codon 13 mutation was present in a low pigmented, mixed cell type melanoma with five mitoses / 10 HPF of a six-year-old female spayed Golden Retriever (No. 57). This dog was still alive 12 months after diagnosis. NRAS mutations in exon 3 (codon 61) were found in nine cases which are summarised in Table 4. 
Table 4. Characteristics of dogs with NRAS exon 3 mutation (codon 61) in digital melanoma $(n=9)$.

\begin{tabular}{|c|c|c|c|c|c|c|c|c|}
\hline Dog No. & $\begin{array}{l}\text { Breed (Coat } \\
\text { Colour) }\end{array}$ & Age (y) & Sex & Toe & Morphology & $\begin{array}{l}\text { Pigment } \\
\text { (Degree) }\end{array}$ & $\begin{array}{l}\text { Mitoses/ } \\
10 \mathrm{HPF}\end{array}$ & $\begin{array}{l}\text { Survival } \\
\text { Time (d) }\end{array}$ \\
\hline 41 & GS & 9 & $\mathrm{M}$ & $\mathrm{RH}$ & epithelioid & 1 & 34 & 83 \\
\hline 42 & GS & 10 & $\mathrm{MC}$ & $\mathrm{LF}$ & epithelioid & 3 & 6 & 52 \\
\hline 43 & GS & 14 & $M$ & $\mathrm{U}$ & epithelioid & $\mathrm{V}$ & 21 & $\mathrm{U}$ \\
\hline 66 & BMD & 8 & M & LH & spindle cell & 2 & 4 & $\mathrm{U}$ \\
\hline 63 & Sheepdog & 9 & M & LF & round & $\mathrm{V}$ & 9 & 48 \\
\hline 70 & Poodle & 11 & $\mathrm{M}$ & $\mathrm{RF}$ & mixed & 3 & 4 & $\mathrm{U}$ \\
\hline 68 & $\mathrm{CS}$ & 11 & FS & $\mathrm{U}$ & spindle cell & 2 & 5 & $\mathrm{U}$ \\
\hline 10 & MG (b\&t) & 14 & $\mathrm{M}$ & $\mathrm{LF}$ & mixed & 2 & 3 & 840 \\
\hline 11 & MG (U) & 8 & $\mathrm{MC}$ & RF & epithelioid & 3 & 3 & A \\
\hline
\end{tabular}

Abbreviations: y: years; d: days; M: male; MC: male castrated; FS: female spayed; RF: right forelimb; RH: right hindlimb; LF: left forelimb; LH: left hindlimb; U: unknown; A: alive; V: varying; b\&t: black and tan; BMD: Bernese Mountain Dog; CS: Cocker Spaniel; GS: Giant Schnauzer; MG: mongrel.

Statistical analysis showed that the degree of pigmentation, mitotic count, degree of nuclear atypia or histomorphological type of digital melanomas, as well as the survival time, were neither significantly associated with RAS mutations in general nor with KRAS mutations. As there were only 11 cases of NRAS mutation, statistical analysis was not performed for NRAS mutations alone to avoid non-reliable data. Regarding the survival times, an empirical median of 142 days was calculated for RAS mutants (KRAS and NRAS), and 183 days for wild types. However, the difference was not statistically significant.

\subsection{Copy Number Variations (CNV) of KITLG}

EDTA blood samples were available from nine animals and examined for copy number variations (CNV) of the KITLG locus. The detected copy numbers varied between four and six (Table 5). Two dogs (Nos. 27 and 73) had copy numbers of five and six, respectively, and showed a mutation in KRAS exon 2 codon 12. Furthermore, a 14-year-old Giant Schnauzer (No. 43) had six copies of the KITLG gene locus in addition to a mutation in NRAS exon 3 codon 61. In two other cases, mutations were found in NRAS exon 2 codon 13 (No. 57) and NRAS exon 3 codon 61 (No. 11), combined with a CNV of four (Table 5).

Table 5. Characteristics of dogs analysed for CNV of $\operatorname{KITLG}(n=9)$.

\begin{tabular}{|c|c|c|c|c|c|c|c|c|c|c|}
\hline Dog No. & $\begin{array}{l}\text { Copy } \\
\text { Number }\end{array}$ & $\begin{array}{c}R A S \\
\text { Mutation }\end{array}$ & $\begin{array}{c}\text { Breed (Coat } \\
\text { Colour) }\end{array}$ & Age (y) & Sex & Toe & Morphology & $\begin{array}{l}\text { Pigment } \\
\text { (Degree) }\end{array}$ & $\begin{array}{l}\text { Mitoses/ } \\
10 \mathrm{HPF}\end{array}$ & $\begin{array}{l}\text { Survival } \\
\text { Time (d) }\end{array}$ \\
\hline 43 & 6 & $\begin{array}{l}\text { NRAS exon } 3 \\
\text { codon } 61\end{array}$ & GS & 14 & M & $\mathrm{U}$ & epithelioid & V & 21 & $\mathrm{U}$ \\
\hline 48 & 5 & - & GS & 10 & $\mathrm{M}$ & RH & epithelioid & 2 & 2 & $\mathrm{~A}$ \\
\hline 73 & 5 & $\begin{array}{c}\text { KRAS exon } 2 \\
\text { codon } 12\end{array}$ & BS & 9 & M & LH & epithelioid & 1 & 13 & $\mathrm{~A}$ \\
\hline 57 & 4 & $\begin{array}{l}\text { NRAS exon } 2 \\
\text { codon } 13\end{array}$ & GR & 6 & FS & $\mathrm{RF}$ & mixed & 1 & 5 & $\mathrm{~A}$ \\
\hline 27 & 6 & $\begin{array}{c}\text { KRAS exon } 2 \\
\text { codon } 12\end{array}$ & LR (black) & 14 & M & RF & epithelioid & 1 & 5 & $\mathrm{~A}$ \\
\hline 61 & 5 & - & IT & 13 & $\mathrm{M}$ & $\mathrm{LF}$ & epithelioid & 0 & 3 & $\mathrm{~A}$ \\
\hline 11 & 4 & $\begin{array}{l}\text { NRAS exon } 3 \\
\text { codon } 61\end{array}$ & MG (U) & 8 & MC & RF & epithelioid & 3 & 3 & A \\
\hline
\end{tabular}


Table 5. Cont.

\begin{tabular}{|c|c|c|c|c|c|c|c|c|c|c|}
\hline Dog No. & $\begin{array}{c}\text { Copy } \\
\text { Number }\end{array}$ & $\begin{array}{c}R A S \\
\text { Mutation }\end{array}$ & $\begin{array}{l}\text { Breed (Coat } \\
\text { Colour) }\end{array}$ & Age (y) & Sex & Toe & Morphology & $\begin{array}{l}\text { Pigment } \\
\text { (Degree) }\end{array}$ & $\begin{array}{l}\text { Mitoses/ } \\
10 \mathrm{HPF}\end{array}$ & $\begin{array}{l}\text { Survival } \\
\text { Time (d) }\end{array}$ \\
\hline 22 & 5 & - & MG (b\&t) & 15 & $\mathrm{M}$ & LH & spindle cell & 1 & 15 & A \\
\hline 21 & 4 & - & MG (black) & 8 & $\mathrm{~F}$ & $\mathrm{RF}$ & round & 1 & 15 & $\mathrm{~A}$ \\
\hline
\end{tabular}

Abbreviations: y: years; d: days; M: male; MC: male castrated; F: female; FS: female spayed; RF: right forelimb; RH: right hindlimb; LF: left forelimb; LH: left hindlimb; U: unknown; A: alive; V: varying; b\&t: black and tan; BS: Belgian Shepherd; GR: Golden Retriever; GS: Giant Schnauzer; IT: Irish Terrier; LR: Labrador Retriever; MG: mongrel.

\section{Discussion}

In this study, the goal was to identify various somatic mutations in canine digital melanoma and to compare these with other canine melanomas, especially oral melanoma. Additionally, the correlation between the mutations and histological criteria of malignancy was investigated. Furthermore, CNV of KITLG were analysed as a germline mutation. The most striking result was the high proportion of KRAS mutations in canine digital melanoma and an increased copy number of KITLG (4-6) was observed. A statistically significant correlation between detected mutations and histomorphological criteria of malignancy and survival time was not found.

Melanoma is a genetically complex disease and the molecular context of BRAF, $R A S$ and $c$-kit gene mutation may affect the response to targeted treatment and even immunology-based therapies in man [40,41]. This is the first study investigating various mutations in a larger number of digital melanomas in dogs. Until now, only few molecular genetic analyses have been performed to compare canine melanomas to their human counterparts [2,42-45]. Moreover, these studies were limited by their retrospective characterisation of cases without complete clinical and pathological data.

In general, the number of canine digital melanomas reported in the literature is rather low (Wobeser et al. $n=52$ [35]; Marino et al. $n=24$ [36]; Schultheiss $n=27$ [37]; Henry et al. $n=10$ [5]). However, in a study on 2912 digital lesions in dogs [7], our working group identified 196 malignant melanomas. None of these studies used molecular methods to examine the digital melanomas. Hendricks et al. [22] analysed RAS, BRAF and c-kit gene mutations, among others, in three digital melanomas, and Chu et al. [29] investigated c-kit mutation in three digital melanomas. It is well known that canine melanocytic neoplasms show very different clinical and pathological features at different sites $[1,3]$. Thus, the hypothesis of the present study was that canine digital melanomas may have different oncogenetic mechanisms than, for instance, oral melanomas. Human acral melanomas have also been studied at the genetic level, with mutations of BRAF $(21.3 \%)$ and KIT genes $(11.5 \% ; 50 \%$ within exon 11$)$ standing out. Here, too, NRAS mutations in codons 12,13 and 61 were found $(27.9 \%)$, but only less than $5 \%$ of cases had activating mutations in HRAS or KRAS [19]. The mutational analysis of the present study was therefore based on the data on human melanoma and studies on canine, mostly oral, melanoma.

Within the canine digital melanomas in our study, we found no BRAF V595E variant. Hendricks et al. [22] did not find any $B R A F$ mutations in 37 canine melanomas-including three originating from the digits. No $B R A F$ mutation was detected in canine oral melanoma (Gillard et al. $n=77$ [2]; Shelly et al. $n=17$ [46]). In contrast, Mochizuki et al. [39] found one $B R A F$ mutation in a canine cutaneous melanoma and two in mucosal melanomas, studying a total of 54 melanomas. Thus, mutations in BRAF seem to not play a relevant role in the pathogenesis of digital melanoma in dogs.

In our screening of canine digital melanomas for $c$-kit mutations, we only found a common polymorphism whose frequency in the dog population is reported to be $18 \%$ (https:/ / www.ebi.ac.uk/eva/?eva-study=PRJEB24066, accessed on 25 November 2020). Comparison with past studies is only possible to a limited extent, because there are currently only a few studies available that have investigated the presence of c-kit mutations in canine melanoma. In those studies, digital melanomas were not represented at all $[2,30,45,47,48]$, 
or they were clearly underrepresented [29]. In summary, c-kit mutations may occur in canine melanoma $[29,30]$, but seem to play a minor role. However, no $c$ - $k i t$ mutation was detected in digital melanoma in previous studies [29]. Since only tumour tissue and no corresponding normal tissue was examined in our studies, it is not possible to verify whether a $c$-kit mutation is of somatic origin or a germline mutation. As we only detected silent alterations in our samples, it was not further investigated and may be clarified in future studies.

To the best of our knowledge, this is the first investigation of copy number variations of KITLG in dogs affected by melanoma. The number of copies varied between four and six in the nine dogs from which blood samples were available for genetic analysis. Mutations in KITLG have been identified as a factor in the oncogenesis of melanoma in man [49]. Germline mutations relevant for tumour predispositions have already been identified in dogs [44]. It is important to keep in mind that a germline mutation may reflect a genetic predisposition rather than the direct somatic oncogenetic pathway like $B R A F$ or $c$-kit mutations. Bannasch et al. [32] found that CNV of KITLG are linked to a variation in the dog's coat colour and pointed out that KITLG is an important factor in melanogenesis. The median number of copies varied from two to eight, depending on the breed and the coat colour [32]. Furthermore, CNV at the KITLG locus have been detected in dogs diagnosed with canine digital squamous cell carcinoma and seem to be involved in its development [33]. In our study, five of nine dogs examined for CNV of KITLG had a dark coat colour ( $n=4$ black; $n=1$ black \& tan) and four of these dogs had more than four copies. Within the remaining four of nine dogs (coat colour: $n=2$ fawn; $n=1$ yellow; $n=1$ unknown), only two dogs were found with more than four copies. Black-coated breeds such as Beauce Shepherds [2], Rottweilers or Schnauzers [2,50] appeared to be predisposed to malignant melanoma in any site while pale-coated dogs, especially solid white-haired breeds, were underrepresented [2]. This is also reflected by the animals in our study, in which most dogs were black $(n=31)$ or black \& tan $(n=15)$ and only 23 dogs were light coloured. As discussed by Grassinger et al. [7], the high number of Giant and Standard Schnauzers in our data set is due to their German origin.

Based on these data, we hypothesise that CNV of KITLG may be involved in the development of melanoma in dogs with dark and black coats. However, the lack of control data makes interpretation of the results difficult. Thus, at the moment, it is impossible to give any breeding recommendations to minimise the risk of digital melanoma in certain dog breeds.

In three canine digital melanomas, Hendricks et al. [22] detected two cases of KRAS mutations and one NRAS mutation. In our study, a much larger sample size was processed: Overall, RAS mutations were detected in $40.7 \%$ of the tumours examined. KRAS exon 2 codons 12 and 13 mutation were detected in 22 of 86 dogs (25.6\%) and KRAS exon 3 codon 61 mutation in two of 55 cases (3.6\%). NRAS exon 2 codons 12 and 13 were mutated in two of 83 cases $(2.4 \%)$, and NRAS exon 3 codon 61 mutation was found in nine of 86 cases $(10.5 \%)$. These results may indicate that $R A S$ mutation could be a driver of mutation in canine digital melanoma. Interestingly, these mutations were mutually exclusive, and we did not identify an additional somatic aberration in any other investigated gene (BRAF, c-kit).

A comparison to canine oral melanoma was also sought. Hendricks et al. [22] reported KRAS mutation rates of $3 \%$ in canine mucosal melanomas. Wong et al. [45] identified this mutation in 5\% of all canine oral melanomas examined in their study. All variants affected the previously described hotspot loci. This supports our hypothesis that canine digital melanomas differ from oral (and mucosal) melanomas at the genetic level, especially regarding the clear difference of detectable KRAS mutations.

Since HRAS alterations are relatively rare in human tumours [16], we did not include this gene in our studies. However, this may be part of future research as our recent findings showed differences between human and canine digital melanoma.

In human medicine, promising results are already available in the field of RAS-targeted treatment of melanomas [14]. There are similar approaches for dogs as well. Wei et al. [51] 
investigated the effect of dual MEK and PI3K/mTOR inhibition on canine melanoma cell lines with ERK and AKT/mTOR activation, and were able to inhibit tumour growth. The study also looked for NRAS mutations, which, however, only occurred in small numbers. Their presence or absence did not seem to be related to ERK activity. Fowles et al. [52] took a similar approach, examining dual inhibition of MAPK and PI3K/AKT in human and canine melanoma and reporting detectable inhibition in both species. They also discussed mutation-independent MAPK and PI3K/AKT activation. Further research in this area is already in progress and seems to be necessary.

The mutations found were examined regarding their diagnostic and prognostic relevance. It is well known that histological criteria, such as mitotic count or degree of pigmentation, can be used to differentiate between benign and malignant melanocytic neoplasms [53]. However, histological criteria, immunohistochemical expression patterns and other prognostic factors were not clearly correlated to survival time in dogs with digital melanomas. Furthermore, in our study, there was no statistically significant difference in the histological criteria (pigmentation, mitotic count, nuclear atypia, and histomorphological type) between dogs with or without $R A S$ mutation. The same applied to the comparison of the KRAS mutant with the KRAS wild type. Thus, KRAS exon 2 and 3 mutations in canine digital melanomas probably have no prognostic relevance. Unfortunately, there were not enough cases with NRAS exon 2 and 3 mutations $(n=11)$ to perform reliable statistics.

According to the literature, $32 \%$ of dogs with malignant digital melanoma had metastases at presentation and another 26\% developed metastases after surgery [36]. Henry et al. [5] reported a metastasis rate of $40 \%$ at the time of diagnosis. Dogs with digital malignant melanoma were reported to have a one-year survival rate of $42 \%$ to $44 \%$ and a two-year survival rate of $11 \%$ to $13 \%$, which reflects the high metastatic rate of the tumour [5,36].

The survival rate of all dogs, including those in which the melanoma diagnosis could not be determined as the confirmed cause of death, was $24 \%$ for one year and $12 \%$ for two years. The one- and two-year survival rates were $14 \%$ and $5 \%$, respectively, within the group that died of melanoma, i.e., already had metastasis at the time of death. The survival rates determined in this study show a similar trend to previous literature $[5,36]$ and confirm the poor prognosis of canine digital melanoma.

The present study was limited by its retrospective nature, where clinical data and exact survival times could only be requested retrospectively and were thus partly incomplete. Future studies could collect this information in a timely manner and make the data more precise. Thus, the statistical analysis of the diagnostic and prognostic relevance of $R A S$ mutations was partly not feasible without producing unreliable data. Whole genome sequencing of digital melanoma in dogs would also be attractive, allowing even more potential genetic mutations to be investigated.

In summary, our initial hypothesis was that canine digital melanoma may differ in its molecular genetic pathway from oral melanoma. This hypothesis was accepted, since we found significantly more KRAS mutations in canine digital melanoma compared to data reported for oral melanoma. Furthermore, a difference is also obvious between canine and human acral melanoma, in which BRAF and KIT mutations occur more frequently.

\section{Conclusions}

It is already known that malignancy and prognosis of canine melanoma strongly depend on the site of the tumour. The present study showed that canine digital melanoma differs from oral melanoma at the molecular genetic level as well. Mutations of the KRAS gene are especially common. In contrast, mutations of BRAF and c-kit genes which are involved in human melanoma obviously do not play a role in the oncogenesis of canine digital melanoma. 
Supplementary Materials: The following supporting information can be downloaded at: https: / / www.mdpi.com/article/10.3390/vetsci9020056/s1. Table S1: Case description, clinical and histomorphological findings of dogs with digital melanoma $(n=86)$.

Author Contributions: Conceptualisation, H.A.-L., R.K. and K.S.; methodology, D.C., A.K., K.S., N.P. and K.F.; validation, A.K., N.P. and H.A.-L.; formal analysis, D.C., A.K., K.S., N.P., C.B. and R.K.; investigation, D.C., A.K., N.P., T.M. and H.A.-L.; resources, H.A.-L., K.S. and N.P.; data curation, D.C., C.B. and N.P.; writing-original draft preparation, D.C.; writing-review and editing, H.A.-L., K.S., N.P. and R.K.; supervision, H.A.-L.; project administration, H.A.-L.; funding acquisition, H.A.-L. and K.S. All authors have read and agreed to the published version of the manuscript.

Funding: This research was funded by BAYERISCHE Forschungsstiftung, grant number AZ-1365-18 within the Forschungsverbund Tumordiagnostik für individualisierte Therapie-FORTiTher, TP-4 (H.A.-L., C.B., K.F.). K.S. and T.M. received funding from SFB1335 (project number 360372040). K.F., K.S. and T.M. received funding from SFB1371 (project number 395357507).

Institutional Review Board Statement: Ethical review and approval were waived for this study due to submission of the samples as part of routine diagnostics at Laboklin GmbH \& Co. KG. Supporting legal basis: RUF-55.2.2-2532-1-86-5.

Informed Consent Statement: Not applicable.

Data Availability Statement: Data available upon request due to privacy/ethical restrictions.

Acknowledgments: We would like to thank our colleagues from the Institute of Pathology, Technische Universität München, Katharina Merkl and Anne Jacob, for the molecular work-up and Olga Seelbach for cutting. We would also like to thank Doreen Girndt for the linguistic revision.

Conflicts of Interest: N.P., Speaker Fee and Travelling Support: AstraZeneca, Illumina, Thermo Fisher Scientific, Roche, Bristol Myers Squibb; Advisory Boards: Bayer, Lilly, Novartis, Roche. K.S., Research Support: Roche; Advisory Board: TRIMT GmbH. The funders had no role in the design of the study; in the collection, analyses, or interpretation of data; in the writing of the manuscript, or in the decision to publish the results. The authors do offer diagnostic, genetic and pathology services.

\section{References}

1. Nishiya, A.T.; Massoco, C.O.; Felizzola, C.R.; Perlmann, E.; Batschinski, K.; Tedardi, M.V.; Garcia, J.S.; Mendonça, P.P.; Teixeira, T.F.; Zaidan Dagli, M.L. Comparative Aspects of Canine Melanoma. Vet. Sci. 2016, 3, 7. [CrossRef] [PubMed]

2. Gillard, M.; Cadieu, E.; de Brito, C.; Abadie, J.; Vergier, B.; Devauchelle, P.; Degorce, F.; Dréano, S.; Primot, A.; Dorso, L.; et al. Naturally occurring melanomas in dogs as models for non-UV pathways of human melanomas. Pigment Cell Melanoma Res. 2014, 27, 90-102. [CrossRef] [PubMed]

3. Spangler, W.L.; Kass, P.H. The histologic and epidemiologic bases for prognostic considerations in canine melanocytic neoplasia. Vet. Pathol. 2006, 43, 136-149. [CrossRef] [PubMed]

4. Bostock, D.E. Prognosis after surgical excision of canine melanomas. Vet. Pathol. 1979, 16, 32-40. [CrossRef]

5. Henry, C.J.; Brewer, W.G., Jr.; Whitley, E.M.; Tyler, J.W.; Ogilvie, G.K.; Norris, A.; Fox, L.E.; Morrison, W.B.; Hammer, A.; Vail, D.M.; et al. Canine Digital Tumors: A Veterinary Cooperative Oncology Group Retrospective Study of 64 Dogs. J. Vet. Intern. Med. 2005, 19, 720-724. [CrossRef]

6. Smith, S.H.; Goldschmidt, M.H.; McManus, P.M. A comparative review of melanocytic neoplasms. Vet. Pathol. 2002, 39, 651-678. [CrossRef]

7. Grassinger, J.M.; Floren, A.; Müller, T.; Cerezo-Echevarria, A.; Beitzinger, C.; Conrad, D.; Törner, K.; Staudacher, M.; AupperleLellbach, H. Digital Lesions in Dogs: A Statistical Breed Analysis of 2912 Cases. Vet. Sci. 2021, 8, 136. [CrossRef]

8. Dhillon, A.S.; Hagan, S.; Rath, O.; Kolch, W. MAP kinase signalling pathways in cancer. Oncogene 2007, 26, 3279-3290. [CrossRef]

9. Mochizuki, H.; Breen, M. Comparative Aspects of BRAF Mutations in Canine Cancers. Vet. Sci. 2015, 2, 231-245. [CrossRef]

10. Davies, H.; Bignell, G.R.; Cox, C.; Stephens, P.; Edkins, S.; Clegg, S.; Teague, J.; Woffendin, H.; Garnett, M.J.; Bottomley, W.; et al. Mutations of the BRAF gene in human cancer. Nature 2002, 417, 949-954. [CrossRef]

11. Brose, M.S.; Volpe, P.; Feldman, M.; Kumar, M.; Rishi, I.; Gerrero, R.; Einhorn, E.; Herlyn, M.; Minna, J.; Nicholson, A.; et al. BRAF and RAS Mutations in Human Lung Cancer and Melanoma. Cancer Res. 2002, 62, 6997-7000. [PubMed]

12. Tsao, H.; Goel, V.; Wu, H.; Yang, G.; Haluska, F.G. Genetic interaction between NRAS and BRAF mutations and PTEN/MMAC1 inactivation in melanoma. J. Investig. Dermatol. 2004, 122, 337-341. [CrossRef] [PubMed]

13. Goel, V.K.; Lazar, A.J.F.; Warneke, C.L.; Redston, M.S.; Haluska, F.G. Examination of mutations in BRAF, NRAS, and PTEN in primary cutaneous melanoma. J. Investig. Dermatol. 2006, 126, 154-160. [CrossRef] [PubMed]

14. Savoia, P.; Fava, P.; Casoni, F.; Cremona, O. Targeting the ERK Signaling Pathway in Melanoma. Int. J. Mol. Sci. 2019, $20,1483$. [CrossRef] [PubMed] 
15. Chapman, P.B.; Hauschild, A.; Robert, C.; Haanen, J.B.; Ascierto, P.; Larkin, J.; Dummer, R.; Garbe, C.; Testori, A.; Maio, M.; et al. Improved survival with vemurafenib in melanoma with BRAF V600E mutation. N. Engl. J. Med. 2011, 364, 2507-2516. [CrossRef]

16. Downward, J. Targeting RAS signalling pathways in cancer therapy. Nat. Rev. Cancer 2003, 3, 11-22. [CrossRef] [PubMed]

17. Bos, J.L. ras oncogenes in human cancer: A review. Cancer Res. 1989, 49, 4682-4689. [PubMed]

18. Cicenas, J.; Tamosaitis, L.; Kvederaviciute, K.; Tarvydas, R.; Staniute, G.; Kalyan, K.; Meskinyte-Kausiliene, E.; Stankevicius, V.; Valius, M. KRAS, NRAS and BRAF mutations in colorectal cancer and melanoma. Med. Oncol. 2017, 34, 26. [CrossRef]

19. Yeh, I.; Jorgenson, E.; Shen, L.; Xu, M.; North, J.P.; Shain, A.H.; Reuss, D.; Wu, H.; Robinson, W.A.; Olshen, A.; et al. Targeted Genomic Profiling of Acral Melanoma. JNCI J. Natl. Cancer Inst. 2019, 111, 1068-1077. [CrossRef]

20. Mayr, B.; Schaffner, G.; Reifinger, M.; Zwetkoff, S.; Prodinger, B. N-ras Mutations in Canine Malignant Melanomas. Vet. J. 2003, 165, 169-171. [CrossRef]

21. Escobar, H.M.; Günther, K.; Richter, A.; Soller, J.T.; Winkler, S.; Nolte, I.; Bullerdiek, J. Absence of Ras-gene Hot-spot Mutations in Canine Fibrosarcomas and Melanomas. Anticancer Res. 2004, 24, 3027-3028.

22. Hendricks, W.P.D.; Zismann, V.; Sivaprakasam, K.; Legendre, C.; Poorman, K.; Tembe, W.; Perdigones, N.; Kiefer, J.; Liang, W.; DeLuca, V.; et al. Somatic inactivating PTPRJ mutations and dysregulated pathways identified in canine malignant melanoma by integrated comparative genomic analysis. PLoS Genet. 2018, 14, e1007589. [CrossRef] [PubMed]

23. Newman, S.J.; Jankovsky, J.M.; Rohrbach, B.W.; LeBlanc, A.K. C-kit expression in canine mucosal melanomas. Vet. Pathol. 2012, 49,760-765. [CrossRef]

24. Yang, Z.; Shi, H.; Ma, P.; Zhao, S.; Kong, Q.; Bian, T.; Gong, C.; Zhao, Q.; Liu, Y.; Qi, X.; et al. Darwinian Positive Selection on the Pleiotropic Effects of KITLG Explain Skin Pigmentation and Winter Temperature Adaptation in Eurasians. Mol. Biol. Evol. 2018, 35, 2272-2283. [CrossRef] [PubMed]

25. Alexeev, V.; Yoon, K. Distinctive role of the cKit receptor tyrosine kinase signaling in mammalian melanocytes. J. Investig. Dermatol. 2006, 126, 1102-1110. [CrossRef] [PubMed]

26. Beadling, C.; Jacobson-Dunlop, E.; Hodi, F.S.; Le, C.; Warrick, A.; Patterson, J.; Town, A.; Harlow, A.; Cruz, F.; Azar, S.; et al. KIT gene mutations and copy number in melanoma subtypes. Clin. Cancer Res. 2008, 14, 6821-6828. [CrossRef] [PubMed]

27. Antonescu, C.R.; Busam, K.J.; Francone, T.D.; Wong, G.C.; Guo, T.; Agaram, N.P.; Besmer, P.; Jungbluth, A.; Gimbel, M.; Chen, C.-T.; et al. L576P KIT mutation in anal melanomas correlates with KIT protein expression and is sensitive to specific kinase inhibition. Int. J. Cancer 2007, 121, 257-264. [CrossRef]

28. Curtin, J.A.; Busam, K.; Pinkel, D.; Bastian, B.C. Somatic activation of KIT in distinct subtypes of melanoma. J. Clin. Oncol. Off. J. Am. Soc. Clin. Oncol. 2006, 24, 4340-4346. [CrossRef]

29. Chu, P.-Y.; Pan, S.-L.; Liu, C.-H.; Lee, J.; Yeh, L.-S.; Liao, A.T. KIT gene exon 11 mutations in canine malignant melanoma. Vet. J. 2013, 196, 226-230. [CrossRef]

30. Smedley, R.C.; Thaiwong, T.; Deeth, L.E.; Kiupel, M. Correlation between KIT Expression and c-Kit Mutations in 2 Subtypes of Canine Oral Melanocytic Neoplasms. Vet. Pathol. 2021, 58, 683-691. [CrossRef]

31. Tani, H.; Miyamoto, R.; Noguchi, S.; Kurita, S.; Nagashima, T.; Michishita, M.; Yayoshi, N.; Tamura, K.; Bonkobara, M. A canine case of malignant melanoma carrying a KIT c.1725_1733del mutation treated with toceranib: A case report and in vitro analysis. BMC Vet. Res. 2021, 17, 147. [CrossRef] [PubMed]

32. Bannasch, D.; Affolter, V.; York, D.; Rebhun, R.; Grahn, R.; Weich, K.; Kallenberg, A. Pigment Intensity in Dogs is Associated with a Copy Number Variant Upstream of KITLG. Genes 2020, 11, 75. [CrossRef]

33. Karyadi, D.M.; Karlins, E.; Decker, B.; vonHoldt, B.M.; Carpintero-Ramirez, G.; Parker, H.G.; Wayne, R.K.; Ostrander, E.A. A copy number variant at the KITLG locus likely confers risk for canine squamous cell carcinoma of the digit. PLoS Genet. 2013, 9, e1003409. [CrossRef] [PubMed]

34. Cerezo-Echevarria, A.; Grassinger, J.M.; Beitzinger, C.; Klopfleisch, R.; Aupperle-Lellbach, H. Evaluating the Histologic Grade of Digital Squamous Cell Carcinomas in Dogs with Dark and Light Haircoat-A Comparative Study of the Invasive Front and Tumor Cell Budding Systems. Vet. Sci. 2020, 8, 3. [CrossRef] [PubMed]

35. Wobeser, B.K.; Kidney, B.A.; Powers, B.E.; Withrow, S.J.; Mayer, M.N.; Spinato, M.T.; Allen, A.L. Diagnoses and clinical outcomes associated with surgically amputated canine digits submitted to multiple veterinary diagnostic laboratories. Vet. Pathol. 2007, 44, 355-361. [CrossRef] [PubMed]

36. Marino, D.J.; Matthiesen, D.T.; Stefanacci, J.D.; Moroff, S.D. Evaluation of dogs with digit masses: 117 cases (1981-1991). J. Am. Vet. Med. Assoc. 1995, 207, 726-728. [PubMed]

37. Schultheiss, P.C. Histologic features and clinical outcomes of melanomas of lip, haired skin, and nail bed locations of dogs. J. Vet. Diagn. Investig. 2006, 18, 422-425. [CrossRef]

38. Kamstock, D.A.; Ehrhart, E.J.; Getzy, D.M.; Bacon, N.J.; Rassnick, K.M.; Moroff, S.D.; Liu, S.M.; Straw, R.C.; McKnight, C.A.; Amorim, R.L.; et al. Recommended guidelines for submission, trimming, margin evaluation, and reporting of tumor biopsy specimens in veterinary surgical pathology. Vet. Pathol. 2011, 48, 19-31. [CrossRef]

39. Mochizuki, H.; Kennedy, K.; Shapiro, S.G.; Breen, M. BRAF Mutations in Canine Cancers. PLoS ONE 2015, 10, e0129534. [CrossRef]

40. Davies, M.A.; Gershenwald, J.E. Targeted therapy for melanoma: A primer. Surg. Oncol. Clin. N. Am. 2011, 20, 165-180. [CrossRef]

41. Portelinha, A.; Thompson, S.; Smith, R.A.; Da Silva Ferreira, M.; Asgari, Z.; Knezevic, A.; Seshan, V.; de Stanchina, E.; Gupta, S.; Denis, L.; et al. ASN007 is a selective ERK1/2 inhibitor with preferential activity against RAS-and RAF-mutant tumors. Cell Rep. Med. 2021, 2, 100350. [CrossRef] [PubMed] 
42. Prouteau, A.; André, C. Canine Melanomas as Models for Human Melanomas: Clinical, Histological, and Genetic Comparison. Genes 2019, 10, 501. [CrossRef] [PubMed]

43. Hernandez, B.; Adissu, H.; Wei, B.-R.; Michael, H.; Merlino, G.; Simpson, R. Naturally Occurring Canine Melanoma as a Predictive Comparative Oncology Model for Human Mucosal and Other Triple Wild-Type Melanomas. Int. J. Mol. Sci. 2018, 19, 394. [CrossRef] [PubMed]

44. Schiffman, J.D.; Breen, M. Comparative oncology: What dogs and other species can teach us about humans with cancer. Philos. Trans. R. Soc. Lond. B Biol. Sci. 2015, 370, 20140231. [CrossRef] [PubMed]

45. Wong, K.; van der Weyden, L.; Schott, C.R.; Foote, A.; Constantino-Casas, F.; Smith, S.; Dobson, J.M.; Murchison, E.P.; Wu, H.; Yeh, I.; et al. Cross-species genomic landscape comparison of human mucosal melanoma with canine oral and equine melanoma. Nat. Commun. 2019, 10, 353. [CrossRef] [PubMed]

46. Shelly, S.; Chien, M.B.; Yip, B.; Kent, M.S.; Theon, A.P.; McCallan, J.L.; London, C.A. Exon 15 BRAF mutations are uncommon in canine oral malignant melanomas. Mamm. Genome 2005, 16, 211-217. [CrossRef] [PubMed]

47. Brocca, G.; Poncina, B.; Sammarco, A.; Cavicchioli, L.; Castagnaro, M. KIT Somatic Mutations and Immunohistochemical Expression in Canine Oral Melanoma. Animals 2020, 10, 2370. [CrossRef]

48. Murakami, A.; Mori, T.; Sakai, H.; Murakami, M.; Yanai, T.; Hoshino, Y.; Maruo, K. Analysis of KIT expression and KIT exon 11 mutations in canine oral malignant melanomas. Vet. Comp. Oncol. 2011, 9, 219-224. [CrossRef]

49. Pho, L.N.; Leachman, S.A. Genetics of pigmentation and melanoma predisposition. G. Ital. Dermatol. Venereol. Organo Uff. Soc. Ital. Dermatol. Sifilogr. 2010, 145, 37-45.

50. Goldschmidt, M.; Goldschmidt, K.H. Epithelial and Melanocytic Tumors of the Skin. In Tumors in Domestic Animals, 5th ed.; Meuten, D.J., Ed.; John Wiley \& Sons Inc.: Ames, IA, USA, 2017; pp. 88-141.

51. Wei, B.-R.; Michael, H.T.; Halsey, C.H.C.; Peer, C.J.; Adhikari, A.; Dwyer, J.E.; Hoover, S.B.; El Meskini, R.; Kozlov, S.; Weaver Ohler, Z.; et al. Synergistic targeted inhibition of MEK and dual PI3K/mTOR diminishes viability and inhibits tumor growth of canine melanoma underscoring its utility as a preclinical model for human mucosal melanoma. Pigment Cell Melanoma Res. 2016, 29, 643-655. [CrossRef]

52. Fowles, J.S.; Denton, C.L.; Gustafson, D.L. Comparative analysis of MAPK and PI3K/AKT pathway activation and inhibition in human and canine melanoma. Vet. Comp. Oncol. 2015, 13, 288-304. [CrossRef] [PubMed]

53. Smedley, R.C.; Spangler, W.L.; Esplin, D.G.; Kitchell, B.E.; Bergman, P.J.; Ho, H.-Y.; Bergin, I.L.; Kiupel, M. Prognostic markers for canine melanocytic neoplasms: A comparative review of the literature and goals for future investigation. Vet. Pathol. 2011, 48, 54-72. [CrossRef] [PubMed] 